\title{
Assessment of ecological quality of hot springs in the Eastern Amhara Region
}

\author{
Sisay Derso ${ }^{1 *}$, Abebe Beyene ${ }^{2}$, Melaku Getachew $^{3}$ and Argaw Ambelu ${ }^{2}$
}

\begin{abstract}
Background: Currently in Ethiopia, Ecotourism is expanding around hot springs, and the increasing recognition of the value of this smokeless industry suggests that there will be a rekindling of interest in thermal springs in the near future. The objective of this study is to examine the relationship between bird diversity with physicochemical water quality and habitat quality of hot springs in Easter Amhara Region.

Methods: A cross sectional study of physical, chemical and biological components of the hot springs was carried out to assess their ecological status. Samples were collected from March to May 2013. Biological samples were collected to provide a qualitative description of the community composition of bird species at each sampling site. Water samples were collected for analysis of selected physicochemical parameters following water quality assessment protocols.

Results: A total of 2484 birds belonging to 56 species were recorded th the 12 sampling sites. Black headed Oriole (Oriolus larvatus), Spur Winged Lapwing (Vanellus spinosus), Spectacled Weaver (Places ocularis) and Yellow Wagtail (Motacilla flava) where the most abundant bird species in the study area and accounts $35 \%$ of the total species. Human disturbance and habitant conditions varied considerably between sites in the study area.

Conclusion: Although human disturbance and water pollution are among the factors influencing ecological quality, there are no strong correlations between physicochemical properties of hot springs and species diversity and this suggests that birds are not the major ecological indicator in hot springs.
\end{abstract}

Keywords: Hot spring, Bird, Ecological status, Diversity, Eastern Amhara

\section{Background}

Thermal springs are the most under researched and underutilized of all natural resources in Ethiopia. Currently in Ethiopia, Ecotourism is expanding around hot springs, and the increasing recognition of the value of this smokeless industry suggests that there will be a rekindling of interest in thermal springs in the near future. The development around this recourse should be ecofriendly and take into accounts, its human and animal health impact. A number of hotels and lodges are constructed on main hot springs, for instance, Sodere, Wondo Genet and Filwuha.

Many Ethiopians believe that water from hot springs can relieve from a number of diseases and is considered

\footnotetext{
*Correspondence: sisdres23@yahoo.com

${ }^{1}$ Environmental Health Research Team, Ethiopian Public Health Institute,

P.O. Box 1242, Addis Ababa, Ethiopia

Full list of author information is available at the end of the article
}

to be the cleanest of all. The study conducted on seven hot springs in Ethiopian revealed that, the high value of chemical species, including bicarbonate, sodium, and conductivity was reported. As a result, if the practice is not hygienic, the water may cause acute infectious diarrhea, repeat or chronic diarrhea episodes, and other non diarrheal disease, which can arise from the chemical species (Haki and Gezmu 2012). Furthermore, several studies have found that geothermal water may contain toxic elements such as arsenic and mercury (Oliver et al. 2011).

The ecological quality and safety of surface waters still today suffer strong degradation because of anthropogenic activities that directly impact the water body. Activity related to agriculture, livestock, industry, and urban complex could alter surface water and its surroundings too. In addition, rivers continue to be used as recipients for all kinds of waste materials, which leading to eutrophication, organic pollution, acidification, and hydrological and

\section{望 Springer}


hydromorphological alterations (Torrisi et al. 2010). A study conducted on the Borkena River of Dessie Kombolcha that encompass many Eastern Amhara hot springs, indicated that the concentration of both conservative and non conservative chemicals increase downstream of the river in both dry and wet seasons (Beyene et al. 2009).

Although water physicochemical analyses can provide a good indication of the pollution level in rivers and streams, these analyses do not consider the state of biological communities. Therefore, end pipe testing cannot properly reflect the condition of freshwater ecosystems. In consequence, over the last decades, the use of biological methods has been promoted and recommended as a useful and complementary technique for the assessment of freshwater pollution (Camargo et al. 2011). Using the biological approaches to determine the ecological effects of pollution have more advantages than determining the pollution with just using physicochemical methods, because physicochemical variables give information about only the situation of water at the time of measuring (Rosenberg and Resh 1993).

Assessment of river health using biological methods is currently common place in most temperate countries. Several of these methods have been standardized and included in national and regional monitoring programs (De Pauw et al. 2006; Hering et al. 2003) serving as a basis for policy decisions concerning surface water management. However, this is not the case in most tropical countries, where physical, chemical methods, some of which require expensive laboratory analysis, are predominantly used to assess surface water quality. Since most tropical regions consist of developing countries, their limited technical and financial resources for environmental issues constrain the establishment of national monitoring programs. Therefore, for these countries, including Ethiopia, cost effective monitoring programs are required. After a process of adaptation, testing, and standardization, biotic indices for biological entities can be reliable systems for application in river management of tropical regions (Dominguez Granda et al. 2011). Biological entities (e.g. bird) are species rich, responds to a broad range of environmental conditions, and are relatively immobile and live in close contact with water body, thereby having the potential for exposure to stresses via both anthropogenic and natural pathways (Brazner et al. 2007).

To ensure environmental sustainability in Ethiopia water resources, ecological indicator systems can support surface water managers to analyze the status of watercourses and to select critical restoration actions. In order to use biological indicator, including bird species as water quality monitoring and assessment tools, Ethiopia needs data from reference as well as disturbed conditions of surface water ecosystems (Ambelu et al. 2010).
Moreover, the concentration of threatened avian species is greater in the tropics than elsewhere. Of the 1029 threatened species, 884 occur in developing countries. Thus, the burden of conserving threatened species lies on the developing nations, where resources are scarce for effective conservation measures (Aynalem et al. 2008). The objective of this study is to examine the relationship between biological parameters (bird diversity) with physicochemical water quality, habitat quality and human disturbance of Hot springs in Easter Amhara Region.

\section{Methods}

\section{Study area}

The study was conducted in three zones of the eastern Amhara region (Fig. 1) . The study area includes Shewa Robit Aregawi hot springs in Kewet district, Shekla and Borkena hot springs in Chefie Dolana district, and Harbu hot springs in Kalu district. These areas located in rift valley regions which are known for several hot springs.

Cheffa Wetland is located $300 \mathrm{~km}$ northeast of Addis Ababa, the capital of Ethiopia in Oromia zone. The wetland is located within $10^{\circ} 32^{\prime}-10^{\circ} 58^{\prime}$ and latitudes and $3946^{\prime}-3956^{\prime} \mathrm{E}$ longitudes in the Borkena and Jara River Basins. Its total area is estimated to be 82,000 ha (Langford et al. 2009; Tamene et al. 2000). The altitude of the wetlands ranges from 1402 to $1520 \mathrm{~m}$ above sea level. This wetland contains many hot springs, which are used for local community as means of traditional healing and as a source of drinking water for domestic purpose and their cattle. Two main sites were selected, Shekla and Borkena, based on their importance in this wetland.

Shekla wetland is located at the entry of the main Cheffa wetland and Borkena site is located at the exit of Cheffa wetland. The Shewarobit Aregawi wetland is located $220 \mathrm{~km}$ away from Addis Ababa, the capital of Ethiopia to Northeast direction in Kewet district, north Shewa.

The Harbu hot spring sampling sites are located $370 \mathrm{~km}$ away from the capital city of Ethiopia in the northeast direction in the Kalu district of South Wollo.

Totally 12 sampling points were selected from the 4 main hot spring sites, i.e., three from each sampling site. Namely Borkena hot spring (B1, B2 and B3), Shekla (S1, S2 and S3), Harbu (H1, H2 and H3) and Shewarobit Aregawi (A1, A2 and A3) were selected based on distance and the temperature gradient.

The Oromo ethnic group constitutes the majority of the people living in the Cheffa Riverine plain and Amhara dominated the Shewarobit Aregawi and Harbu areas in the Eastern Amhara region. Subsistence mixed agriculture (crop production and livestock rearing) is the mainstay of the permanent wetland population. The population of the nearby Woredas (districts) of Dewa Cheffa, 
Artuma Fursi, Kemise Town, Antsokiya Gemza, Efratagidim and Kalu was 614,476 during the 2007 census. In the absence of census data, we estimate that fewer than 10,000 people live in about two dozen villages in Cheffa Wetland, 2000 in Harbu, and about 3000 in Shewarobit Aregawi sites. These major wetlands which are home of several hot springs are periphery with middle towns with population size above 20,000 populations (Getachew et al. 2012).

During the dry season, Afar, Oromo, Argoba, and Amhara pastoralists move with their herds to these Wetlands (MCKEE 2007; Getachew et al. 2012). In 2002, the United Nations Emergencies Unit for Ethiopia reported that about 50,000 pastoralists together with 200,000 livestock, mostly cattle, used the Cheffa Wetlands for watering and grazing (Piguet 2002). The same scenario also noticed during our survey time in Shewarobit and Harbu hot spring sites. The Shewarobit wetland is converted to farmland in alarming rates than any of the other sites in our study. The site was used for harvesting of many vegetables, fruit, cereal crops, and tobacco plant. The site also degraded by hundreds of cattle grazing, firing and conversion of wetland to farm land. This site comprised two churches, which being used as holy water sites. In daily basis, hundreds of people were getting healing services in these churches. These people practiced open defecation, washing clothes with soap and no any means of waste management practices. This situation was observed predominantly in Aregawei church that comprised four main hot springs in the wetland. In addition, In Harbu site, this scenario was experienced.

\section{Sampling sites and sampling frequency}

Bird species and water samples were collected at 12 sampling sites. Sampling sites were selected based on criteria of the distance between sampling points, difference of water temperature, and the basis of factors such as: ease of access, variety of habitats, proximity to a local point source of pollution, e.g., a factory, a drainage canal or Proximity to a non point source of pollution, e.g., a farm (UN HABITAT 2005). The selected sites were representative of the local catchment characteristics. Water samples were taken simultaneously with the bird species count. Samples were collected from February to April 2013 in mid and near the end of the dry season period in the study area. At each site, 21 water sample was taken (two replicates per site per sampling date) and were analyzed for physicochemical parameters during the sampling period. To obtain a visual record of sampling sites, digital photographs of the water body, upstream and downstream of the sampling locations were taken during sampling periods. Furthermore, for integration into a Geographic Information System (GIS) database, longitude and latitude, and elevation of each sampling site were recorded using a global positioning system unit (Magellan ${ }^{\circledR}$, SporTrak Pro).

\section{Study design}

A cross sectional study of physical, chemical and biological components of the hot springs was carried out to assess its ecological status.

\section{Bird count and identification}

The method of total count (direct counts) was employed to census the bird population (USEPA 2002). In this method, representative sites were identified and the birds at these sites were counted using field binoculars. Observations were carried out for $5 \mathrm{~h} ; 6: 30$ to 10:00 and 16:30 to $18: 00 \mathrm{~h}$, during these lapses, the activities of birds became prominent. Birds were identified using physical features with the help of field guides and reference books on the bird fauna of East Africa (Perlo 2009). Photographs and videos were taken to justify the species type for those species, which were difficult to identify. Some inconspicuous bird species were also identified based on their calls (Aynalem and Bekele 2008).

\section{Water quality assessment}

Two liters of water samples were collected for analysis of nitrate nitrogen $\left(\mathrm{NO}_{3} \mathrm{~N}\right)$, Orto phosphate $\left(\mathrm{PO}_{4}^{3}\right)$, and total Nitrogen (TN), and chloride concentration in laboratory. On the other hand, water temperature, $\mathrm{pH}$, and conductivity, dissolved oxygen (DO), and turbidity were measured on site using a $\mathrm{HACH}$ multimeter handheld probe, model HQ40D. The collected water samples were transported to Jimma University, Environmental Health Science and Technology Department Laboratory in an insulated box containing ice packs. A spectrophotometer, model HACH DR 5000, and a digester, model HACH LT200, were used to determine total nitrogen. The kits were used for determination of total nitrogen was LCK 138 following the procedures set for the parameter. Orto phosphate concentration was determined by the stannous chloride method and Nitrate $\mathrm{N}$ concentration was measured by ultraviolet spectrophotometer screening method as well Chloride concentrations was determined by the argentometric method (APHA 1995).

\section{Habitat quality assessment (HQA)}

Physical habitat information was collected at each site with visual estimate measurement technique. At each of six evenly spaced channel cross sections, wetted width, bank full width, bank full and incised heights, and bank angles were estimated. Canopy cover was measured on the left and right bank, and in four directions (upstream, downstream, left, and right) in the center of the channel 
cross section as partly open, partly shaded or shaded. Stream water depth was measured at five equally spaced locations along each cross section. Substrate composition was determined by size tall, performed by placing a finger into the water and classifying the size of the particle first touched as bedrock $(>4000 \mathrm{~mm})$, boulder (250-4000 mm), cobble (64-250 mm), coarse gravel (16$64 \mathrm{~mm})$, fine gravel $(2-16 \mathrm{~mm})$, sand $(0.06-2.00 \mathrm{~mm})$, fines $(<0.06 \mathrm{~mm})$, wood, hardpan (firm, consolidated fines), or other. Embeddedness percentage was visually estimated from the area immediately surrounding each sampled particle. Immediately following cross section surveys, large wood ( $>6$ in diameter) was tallied and organic layer accumulation in depositional zones was measured. Visual estimates or classifications were then made of dominant bank material, percent stable bank, percent undercut bank, dominant original bed material and dominant depositional bed material, original habitat embeddedness (\%), and depositional habitat embeddedness. On each bank, the riparian zone buffer width (defined for this study as the area within which natural matures vegetative communities occurred) and the dominant adjacent land uses outside the riparian buffer area were recorded. The reach was also classified using the Rosgen Level 2 stream morphology, classification system (Rosgen 1996). This system classifies stream reaches based on channel slope, dominant channel materials, channel entrenchment, the width to depth ratio, and sinuosity. Streams were classified using this system to more precisely characterize high and low gradient reaches in relation to morphological features. The habitat conditions of the hot springs were evaluated based on the method developed by Barbour et al. (1999) and human and animal impact assessment was made following the methods of the Maine Department of Environmental Protection (MDEP 2009).

\section{Data analysis}

The Shannon diversity index (Turkmen and Kazanci 2010), Simpson diversity index (Smith and Wilson 1996) and Margallef diversity index (Gamito 2010) were used to measure the diversity of bird which were recorded at the 12 sampling sites. Bray Curtis cluster analysis, Shannon, Simpson and Margallef diversity index were calculated from bird species of each site using Bio Diversity Pro 2.0 Professional freely available software. The physicochemical and bird species, as well as other environmental variables of hot water were analyzed by Past freely available software to identify influencing parameters on birds of the Eastern Amhara hot springs. Before running past, the biological and environmental data were transformed using square root and $\log (x+1)$, respectively.
Multiple regression analysis was performed to analyze the existence of linear relationship between biological data represented by Shannon diversity indexes, Simpson diversity index and other biotic indices (bird community) and the environmental variables by stepwise forward selection method to select the best environmental predictors using STATISTICA ${ }^{\circledR}$ software package version 7.1. Prior to the analysis, the environmental data were transformed to $\log (x+1)$, where $x$ is the value of an environmental variable.

\section{Result}

\section{Physicochemical characteristics of water samples}

The values of the physicochemical examination of samples from the different sites are shown in Table 1. Values vary considerably among the 12 sites. Water temperature levels were particularly high at the $\mathrm{B} 1, \mathrm{H} 1, \mathrm{~S} 1$, and the A1 sites where the hot springs emerged. The turbidity level was ranging from 4.4 to $33.8 \mathrm{NTU}$ in all sites except high turbidity level at site $\mathrm{S} 2$ that was $185 \mathrm{NTU}$. The $\mathrm{pH}$ values of all water samples were within the range of 7.09-8.63. Dissolved oxygen was generally low at emerging sites of hot springs even null at $\mathrm{H} 1$ and $\mathrm{B} 1$ sites. The electric conductivity was high, particularly at the sites of S2, S1, and A2. On the other hand, the EC is very low at A1 and S3 sites where the water was submerged into sands before the sampling sites. The rest sites were at similar pattern in the EC value fallen in the range of 974-1398. Generally, the water depth of all sampling sites was shallow and had a low flow rate. The nutrient values were distributed in a similar pattern except other phosphorus and nitrate nitrogen exceed in $\mathrm{S} 2$ and $\mathrm{H} 3$ sites than the rest sites. The chloride concentration of $\mathrm{H} 3$ site was greater than the other sites of hot springs (Table 1) (Fig. 1).

\section{Principal component analysis of environmental variables}

A bi plot of the sampling sites and environmental variables showed that there was a clear distinction between sampling sites (Fig. 2). Conductivity, ortho phosphate, altitude, Nitrate $\mathrm{N}$ and chloride were strongly negatively correlated with $\mathrm{H} 2, \mathrm{~S} 2$ and $\mathrm{H} 3$, whereas TN, discharge, $\mathrm{pH}$, velocity and DO were more correlated with A2, A3, B3 and B2 sampling sites. Water depth solely was correlated with $\mathrm{A} 1$ and sites of B1. H1 and S1 were not correlated with any of these environmental variables. S3 site association was relayed at the $\mathrm{x}$ axis between component 1 and component 2 .

\section{Cluster analysis of environmental variables}

The hierarchical cluster analysis of environmental variables (Fig. 3) showed that the sampling sites possibly classified into three main categories. The first categories, samples from low electrical conductivity values; the 


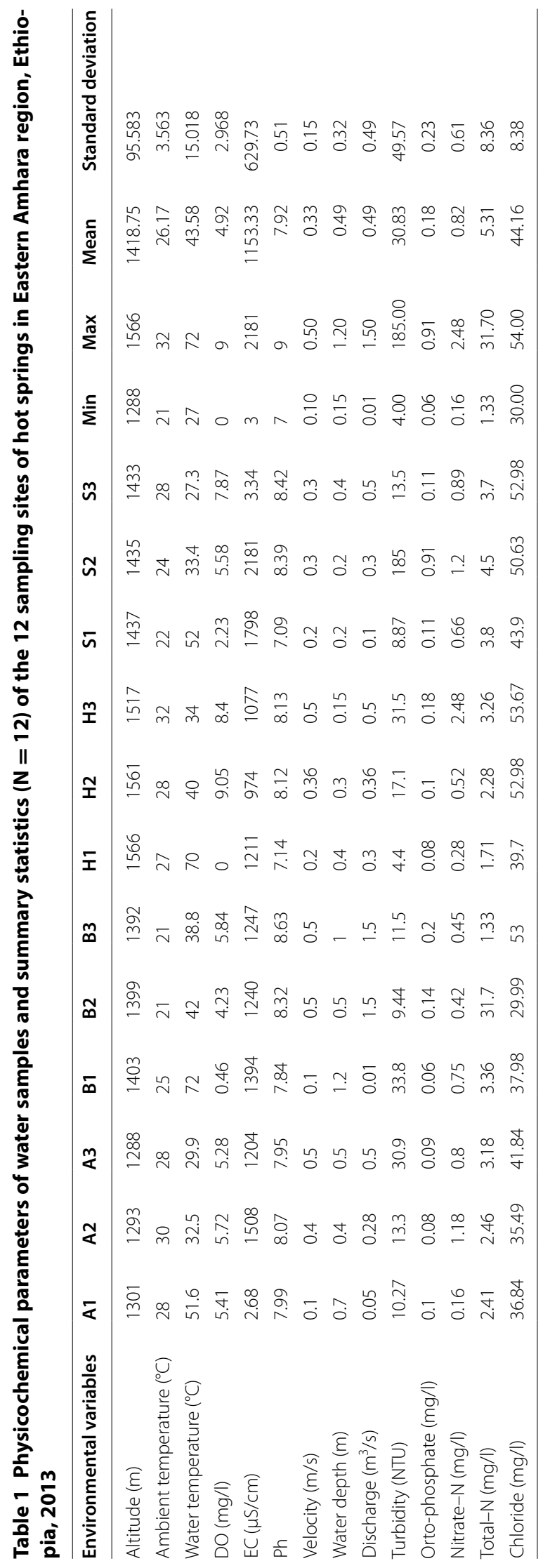




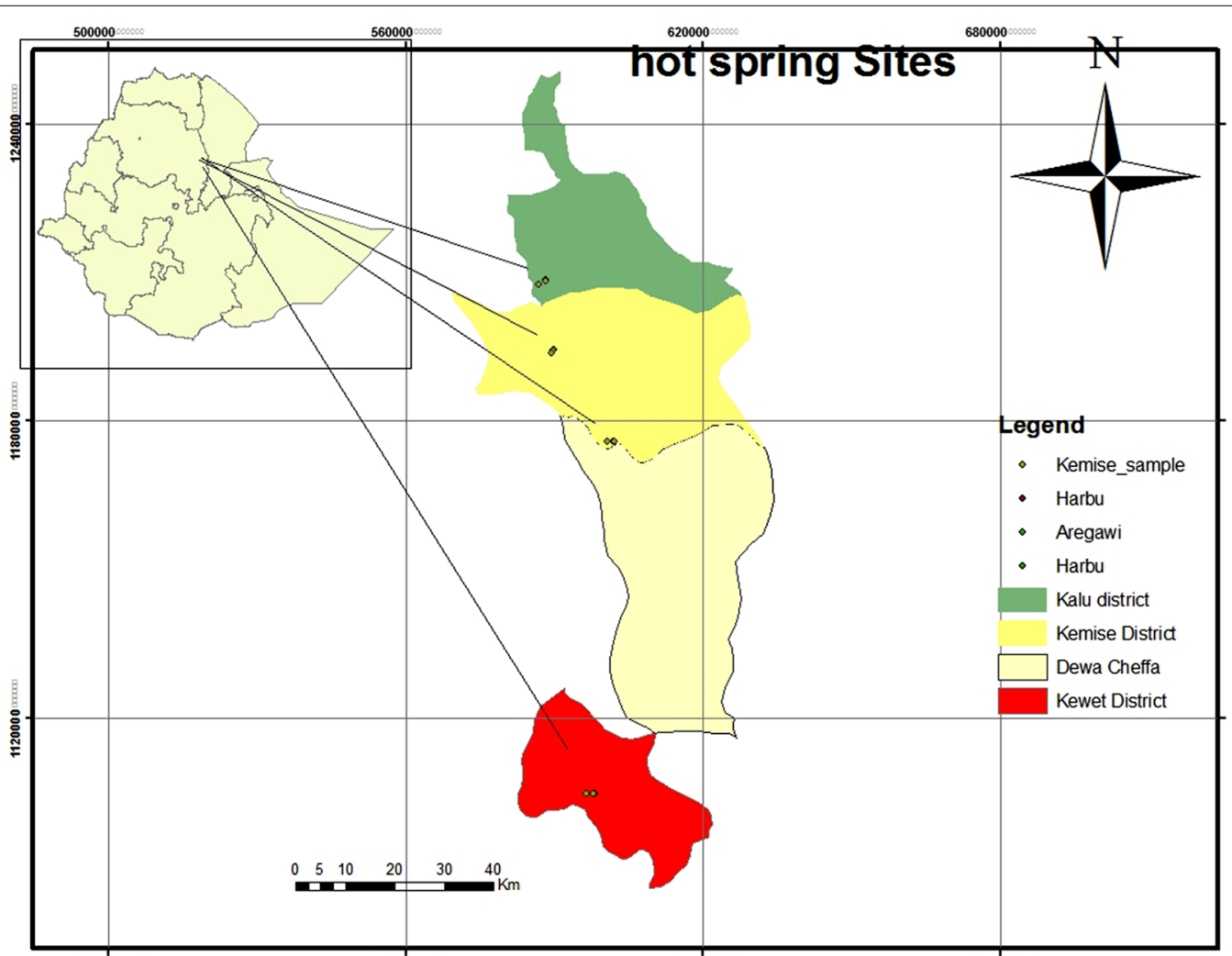

Fig. 1 Hot spring sampling sites in East Amhara Region, Ethiopia

second group with samples characterized by similar turbidity and velocity parameters, and the last possible group was established based on average $\mathrm{pH}$ and velocity value.

\section{Influence of water temperature on biotic indices}

Water temperature has weak correlation with a Shannon diversity of birds and it is correlated negatively (Fig. 4). This may be due to the short distance within sampling sites that enable birds to mobile, and it's also because of other confounding factors, including similar pattern of habitat quality index and human disturbances scores in all studied sites.

\section{Human disturbance score and habitat quality index}

Human disturbance score in the habitats studied varied considerably among sites. 10 of the 12 sites had total human disturbance scores greater than B2 and B3, which had moderate disturbance class (Table 2).

Habitant quality index of A3, B2 and B3 were classified as sub optimal and $\mathrm{B} 1, \mathrm{H} 1$ and $\mathrm{S} 1$ were categorized as poor conditions and the rest six sites were categorized as marginal condition class and none of the sites were characterized by optimum conditions (Table 2).

\section{Bird diversity}

A total of 2484 birds belonging to 56 species were recorded at the 12 sampling sites. Black headed Oriole (Oriolus larvatus), Spur Winged Lapwing (Vanellus spinosus), Spectacled Weaver (Places ocularis) and Yellow Wagtail (Motacilla flava) where the most abundant bird species in the study area, accounting 10.5, 8.75, 8.4 and $7.8 \%$ of all species recorded, respectively. The largest number of species (23) was recorded at the Shekla (S1, S2 and S3) sites and the largest number of birds (441) was observed at the B1 site.

\section{Shannon diversity Index}

The Shannon diversity index of birds was lower at six sites $(\mathrm{H} 1, \mathrm{H} 2, \mathrm{H} 3, \mathrm{~B} 1, \mathrm{~B} 2$ and $\mathrm{B} 3)$ showed the index between 0.72 and 0.9 . However, the index calculated based on bird communities at six sites (S1, S2, S3, A1, $\mathrm{A} 2$ and A3) showed above 1 and the range from 1.153 to 1.187 (Table 3).

\section{Simpson diversity index}

The Simpson diversity index of bird communities was also significantly lower at all 12 sites where birds studied, which was ranging from 0.08 to 0.319 as shown Table 3. 


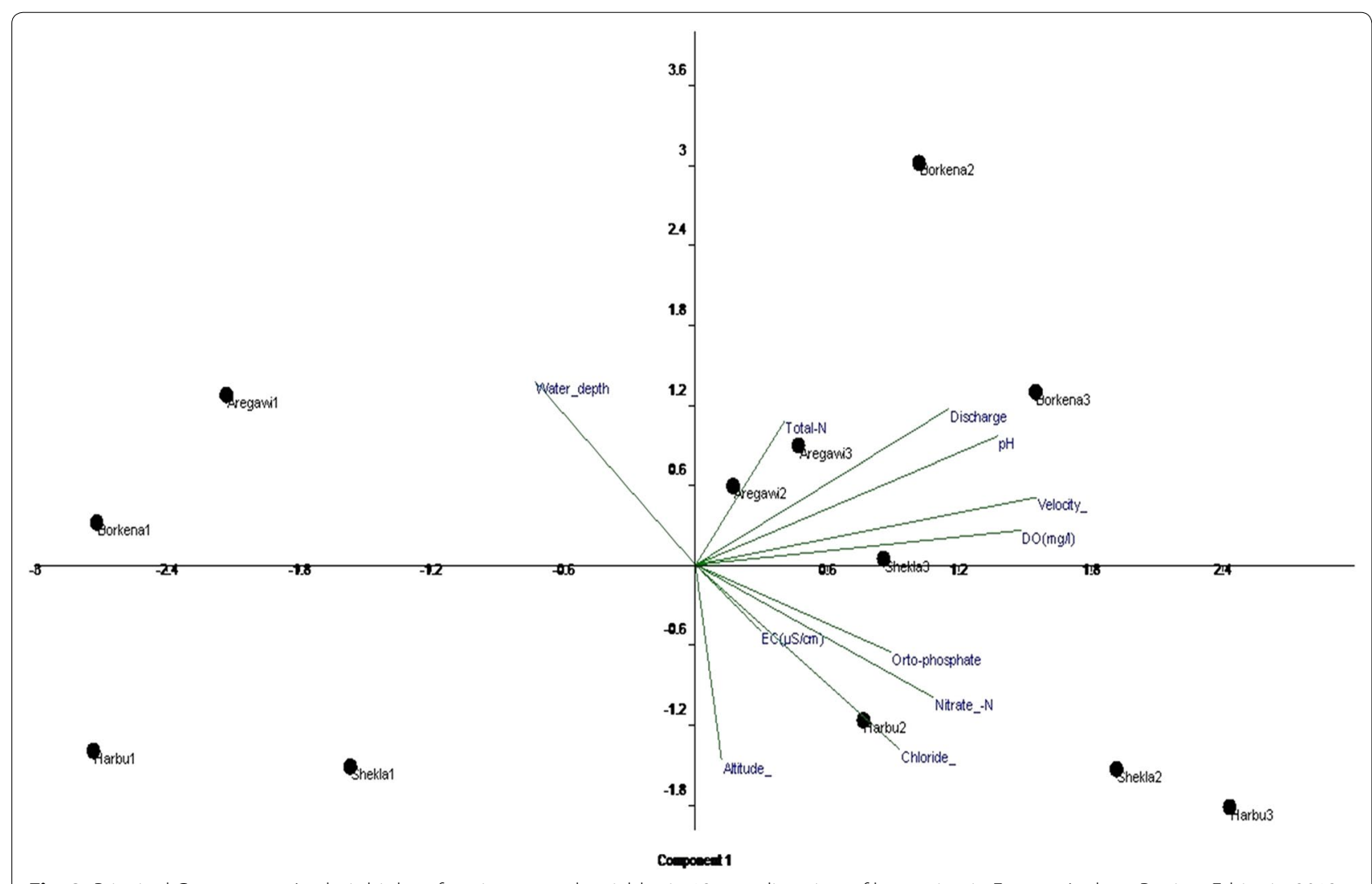

Fig. 2 Principal Component Analysis biplot of environmental variables in 12 sampling sites of hot spring in Eastern Amhara Region, Ethiopia, 2013

\section{Margaleff diversity index}

The values of the Margaleff diversity index of bird were between 20.798 and 25.015 (Table 3). The lowest value was for $\mathrm{B} 1$ and the highest was for $\mathrm{H} 1, \mathrm{H} 2$ and $\mathrm{H} 3$ (Fig. 5). This index shows variation depending on number of species, so that the number of individuals is less important for calculating.

\section{Multivariate analyses of bird data}

The hierarchical cluster analysis from bird (Fig. 6) indicated that the sampling sites could be grouped into three major classes. The first category $(\mathrm{H} 3, \mathrm{H} 1$ and $\mathrm{H} 2)$ included samples from stream sites without any wetlands. The second group (A3, A1, A2, S3, S1 and S2) incorporated samples from both wetland and streams and the third class (B2, B3 and B1) consists sample of typically wetlands.

\section{Discussion}

The diversity of birds, habitant condition and water quality were heavily affected by anthropogenic activities, which carried out on the water body as well as in the surrounding area of hot springs in the Eastern Amhara Region. The high turbidity and chloride concentration, low dissolved oxygen values (Table 1) might be mainly due to organic pollution from animal excrements and sewage discharges from towns, villages, and hot springs temporary residence tents, which practiced open defecation around the springs. Another study conducted in the Borkena valley also found that the main cause of water quality deterioration and biodiversity decline in wetlands were activities associated with agriculture, overgrazing and deforestation (Getachew et al. 2012). Another study conducted in Kenya also revealed that, there were clear effects of catchment on some physicochemical measures like conductivity and turbidity, which were significantly higher at sites with high disturbance and agriculture use (Minaya et al. 2013).

All the hot spring sites had high electrical conductivity value (Table 1) this may be due to the texture of mineral soil and the degree of humification of organic soil. Similar finding was obtained in the same study area in the Borkena valley for non hot spring sites (Getachew et al. 2012) as well in Kenya showed that electrical Conductivity was identified as an indicator of anthropogenic activities use (Minaya et al. 2013).

In all four upstream catchment areas, the water flow was very low (Table 1) compared to downstream sites. 


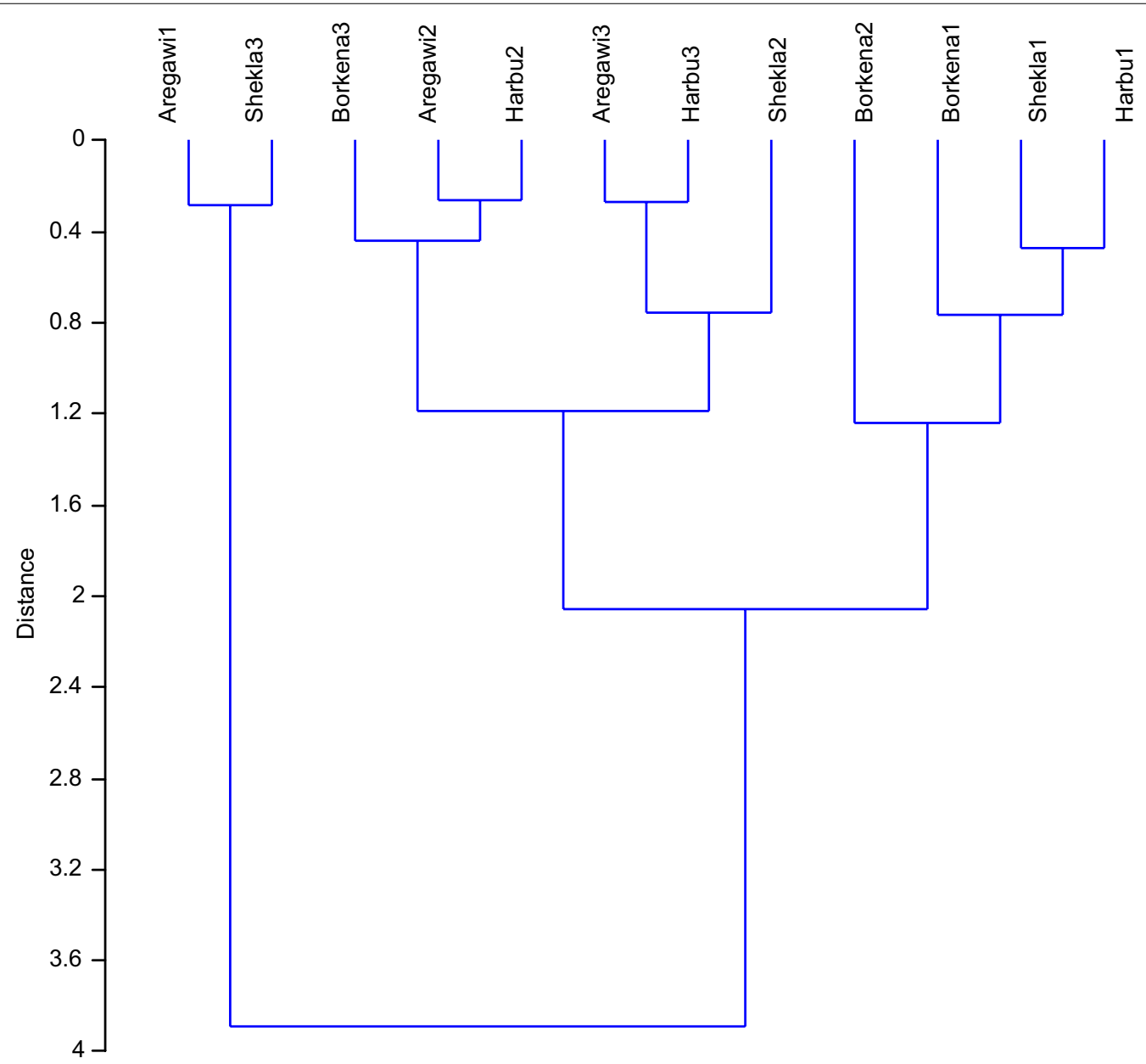

Fig. 3 Cluster analysis (single link) based on environmental data in 12 sampling sites of hot springs in Eastern Amhara Region, Ethiopia, 2013

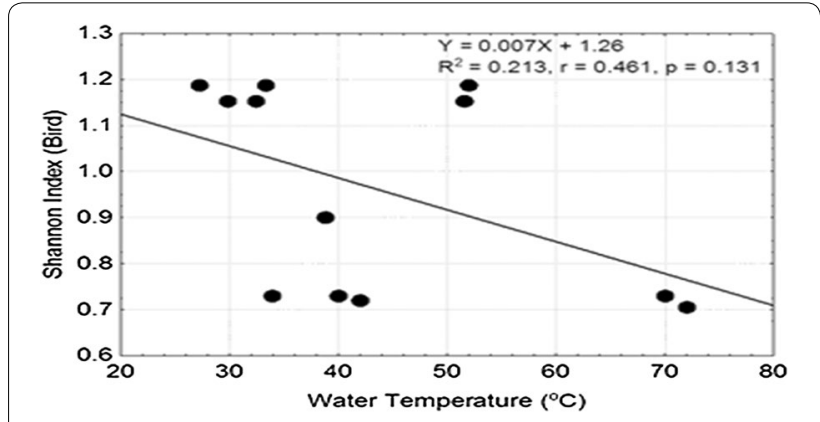

Fig. 4 The influence of water temperature on bird biotic indices in 12 hot spring sites in East Amhara Region, Ethiopia, 2013

As we witnessed during the survey all this upstream sampling sites using for community as the holy water sites, sources of drinking water and other domestic purposes. Moreover, community constructed local reservoir, installed piping system and conduit at the source of the springs to distribute to their pilgrims in B1, A1 and $\mathrm{H} 1$ sites. Another study conducted in South Africa revealed that, extent of different land use and magnitude of impact of each land use in reducing water quantity and quality (Kotze et al. 2012).

Water temperature, dissolved oxygen (DO), total Nitrogen, and turbidity varied among sampling sites. Among the physicochemical variables, $\mathrm{pH}$ remained within acceptable ranges of surface water standards in each site, but not the other variables (Table 1). The Shannon diversity index (Fig. 7) revealed that, the bird communities had higher diversities at A2, A3, B3, and S2 than the remaining eight sampling sites. Nevertheless, the diversity of Shannon index was lower than the previous study conducted for non hot spring areas sites (Getachew et al. 2012), in Cheffa wetland, North East Ethiopian.

Most value measured using the Shannon diversity index (Turkmen and Kazanci 2010) range from 1.5 to 3.5 , rarely exceeding 4.5 . Values above 3.0 indicate that habitat structure is stable and balanced and values below 
Table 2 Habitant and human impact score in 12 sampling sites of hot springs in Eastern Amhara Region, Ethiopia, 2013

\begin{tabular}{|c|c|c|c|c|}
\hline \multirow[t]{2}{*}{ Sampling site } & \multicolumn{2}{|c|}{ Human impact } & \multicolumn{2}{|c|}{ Habitat condition } \\
\hline & Score & Class & Score & Class \\
\hline A1 & 100 & Severe & 83 & Marginal \\
\hline A2 & 104 & Severe & 106 & Marginal \\
\hline A3 & 100 & Severe & 124 & Sub-optimum \\
\hline B1 & 105 & Severe & 34 & Poor \\
\hline B2 & 74 & Moderate & 142 & Sub-optimum \\
\hline B3 & 67 & Moderate & 146 & Sub-optimum \\
\hline $\mathrm{H} 1$ & 105 & Severe & 59 & Poor \\
\hline $\mathrm{H} 2$ & 87 & Severe & 91 & Marginal \\
\hline $\mathrm{H3}$ & 93 & Severe & 79 & Marginal \\
\hline S1 & 105 & Severe & 50 & Poor \\
\hline $\mathrm{S} 2$ & 97 & Severe & 93 & Marginal \\
\hline S3 & 95 & Severe & 92 & Marginal \\
\hline
\end{tabular}

Habitat condition score poor <60, marginal 60-109, sub-optimum 110-159 and optimum 160-200 (Barbour, Gerritsen, Snyder, and Stribling, 1999), and low disturbance $<25$, moderate disturbance $>25-75$ and sever disturbance $>75-125$ (MDEP 2009)

Table 3 The Shannon, Simpson and Margaleff diversity index of bird community in 12 sampling sites of hot springs in Eastern Amhara, Ethiopia, 2013

\begin{tabular}{llllll}
\hline Site name & $\mathbf{H}^{\prime}$ & Hmax & $\mathbf{J}^{\prime}$ & $\mathbf{D}$ & $\mathbf{M}$ \\
\hline A1 & 1.153 & 1.322 & 0.872 & 0.088 & 24.832 \\
A2 & 1.153 & 1.322 & 0.872 & 0.088 & 24.832 \\
A3 & 1.153 & 1.322 & 0.872 & 0.088 & 24.832 \\
B1 & 0.705 & 1.255 & 0.562 & 0.295 & 20.798 \\
B2 & 0.72 & 0.954 & 0.754 & 0.269 & 24.185 \\
B3 & 0.9 & 1.23 & 0.731 & 0.184 & 23.727 \\
H1 & 0.729 & 1.146 & 0.636 & 0.319 & 25.015 \\
H2 & 0.729 & 1.146 & 0.636 & 0.319 & 25.015 \\
H3 & 0.729 & 1.146 & 0.636 & 0.319 & 25.015 \\
S1 & 1.187 & 1.362 & 0.872 & 0.08 & 23.344 \\
S2 & 1.187 & 1.362 & 0.872 & 0.08 & 23.344 \\
S3 & 1.187 & 1.362 & 0.872 & 0.08 & 23.344 \\
\hline
\end{tabular}

$\mathrm{H}^{\prime}=$ Shannon $\mathrm{H}^{\prime}$ Log base 10, Hmax = Shannon Hmax L of Base 10,

$J^{\prime}=$ Shannon $J^{\prime}, D=$ Simpson diversity and $M=$ Margaleff $M$ Base 10

1.0 indicate the presence of pollution and degradation of habitat structure. Based on these criteria, none of the study sites of hot springs in the Eastern Amhara region exceeded the 1.5 level of the Shannon diversity index, for birds (Table 3). Especially, bird Shannon diversity index was below 1 at $50 \%$ of the sites studied. Similarly, the Shannon diversity index for similar study conducted in Cheffa Wetland for normal streams was below one, further indicating the presence of elevated levels of pollution and degradation of habitat structure in the studied area (Getachew et al. 2012).

According to Smith and Wilson (1996), values measuring using the Simpson diversity index range between zero and one. Zero represents minimum evenness and one for the maximum. Based on this fact, all the sites fallen to nearly zero and indicated the presence of severe pollution in all sites of the hot springs (Figs. 6, 8).

Multivariate analysis of most environmental variables with biotic indices were not significant except water temperature. A linear relationship was found between water temperature and Bird based biotic indices. The rest, environmental variables did not show strong association with biological indices of the bird community. In addition, the bird diversity index was not showing strong correlation with each other too. The Shannon diversity index and family level biotic index calculated based on bird diversity did not show strong association with water temperature (Fig. 4). This may be due to the short distance within sampling sites that enable birds to mobile, and it's also because of other confounding factors, including similar pattern of habitat quality index and human disturbances scores in all studied sites.

The habitat classes of the Eastern Amhara region hot springs could be generalized into three major class (marginal, sub optimal, and optimal) as shown from Table 2. Moreover, the diversity of wetland birds was lower than other studies conducted in Cheffa wetlands (Getachew et al. 2012) and another studies in Lake Tana (Aynalem and Bekele 2008). This might be linked to habitat destruction resulting from human activities. As we noticed during data collection, farmers were firing and cutting vegetation to convert to farmland and plowing the wetland parts. And currently cultivation was practiced in majority of Aregawi wetland. The study conducted (Mekonnen and Aticho 2011) in Jimma, Ethiopia indicated that, a shortage of agricultural land and decrease of agricultural land productivity, the surrounding communities forced to drain the wetland for crop cultivation, in order to meet their needs. Generally, wetlands around the hot springs, which used for the production of birds, were severely deteriorated by human activities, including over grazing, intensive farming, and open burning so as to convert to farmlands as noticed during the survey.

These results indicated that, the water quality at all 12 sites has been degraded to varying degree because of human activities (Table 2). The observed low diversity of birds (Table 3 ) in the Wetlands feeding by hot springs were in agreement with other studies in the same wetland (Getachew et al. 2012) and the other study in Ethiopia (Aynalem and Bekele 2008). Those studies revealed that, in natural habitats where human interference is relatively small, the diversity and abundance of species are greater 


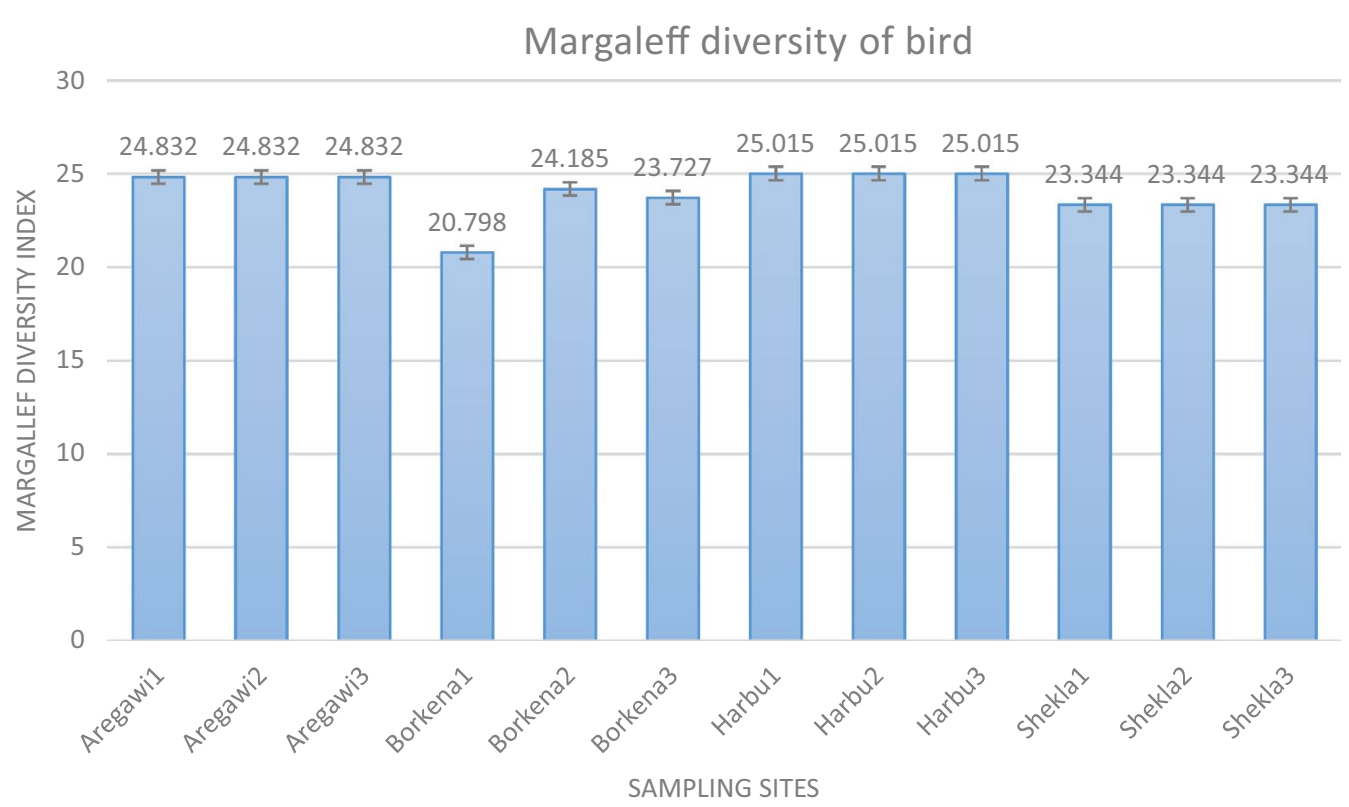

Fig. 5 Average Margaleff calculated from birds in 12 sampling sites of hot springs in East Amhara region, Ethiopia, 2013

than in fragmented habitats and where intensive farming

et al. 2010). Papyrus vegetation, indispensable for many

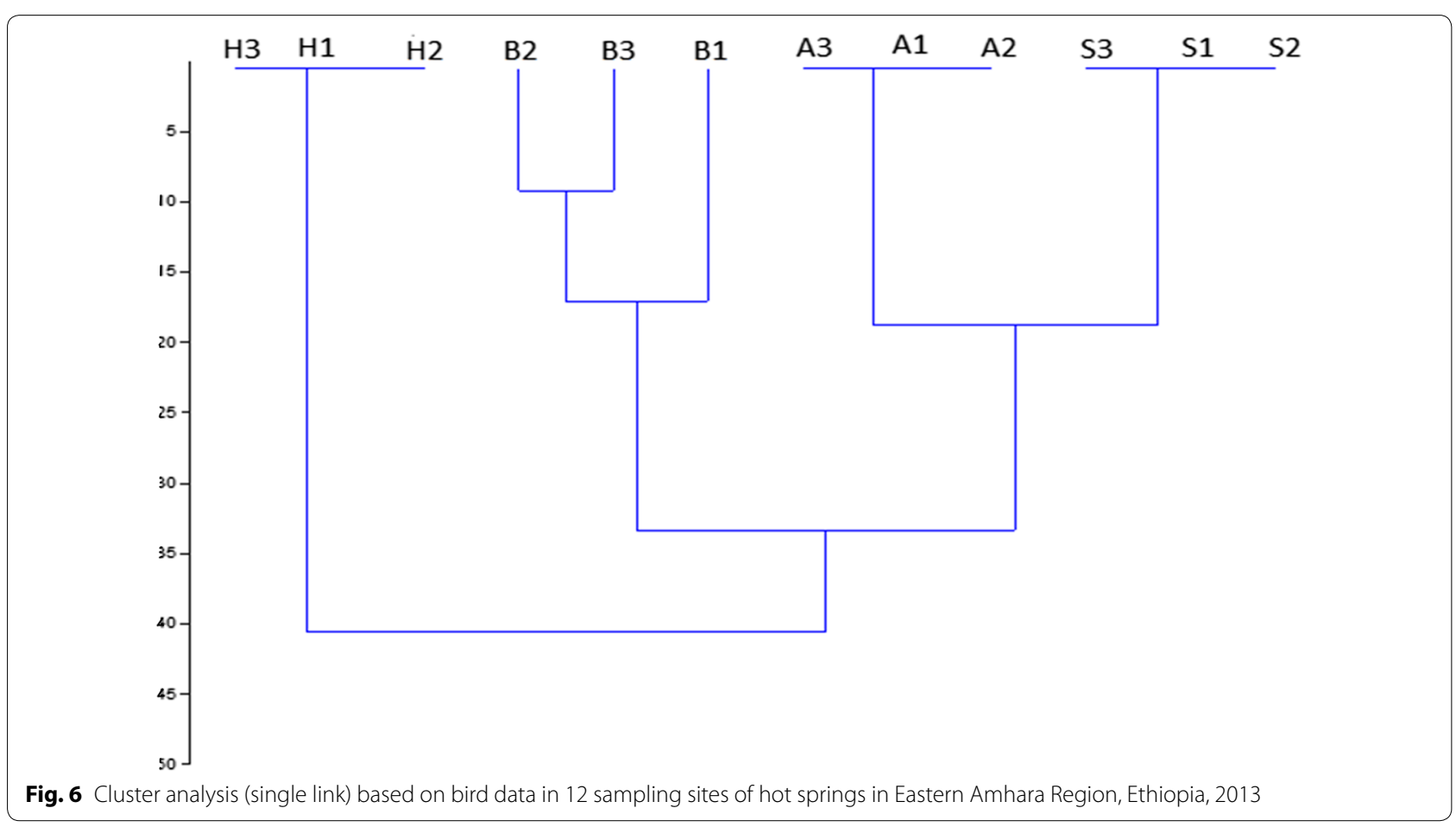

is carried out. The changes in this bird diversity reflected the hydrological modifications induced by agriculture at the watershed scale, which have significant effects on the relative representation of wetland habitats (Robledano wetland bird species, was degraded because of its heavy use by the local community, for contribution involves like as local hunt building material, selling to nearby community as source of income, serving as grazing). The loss of 


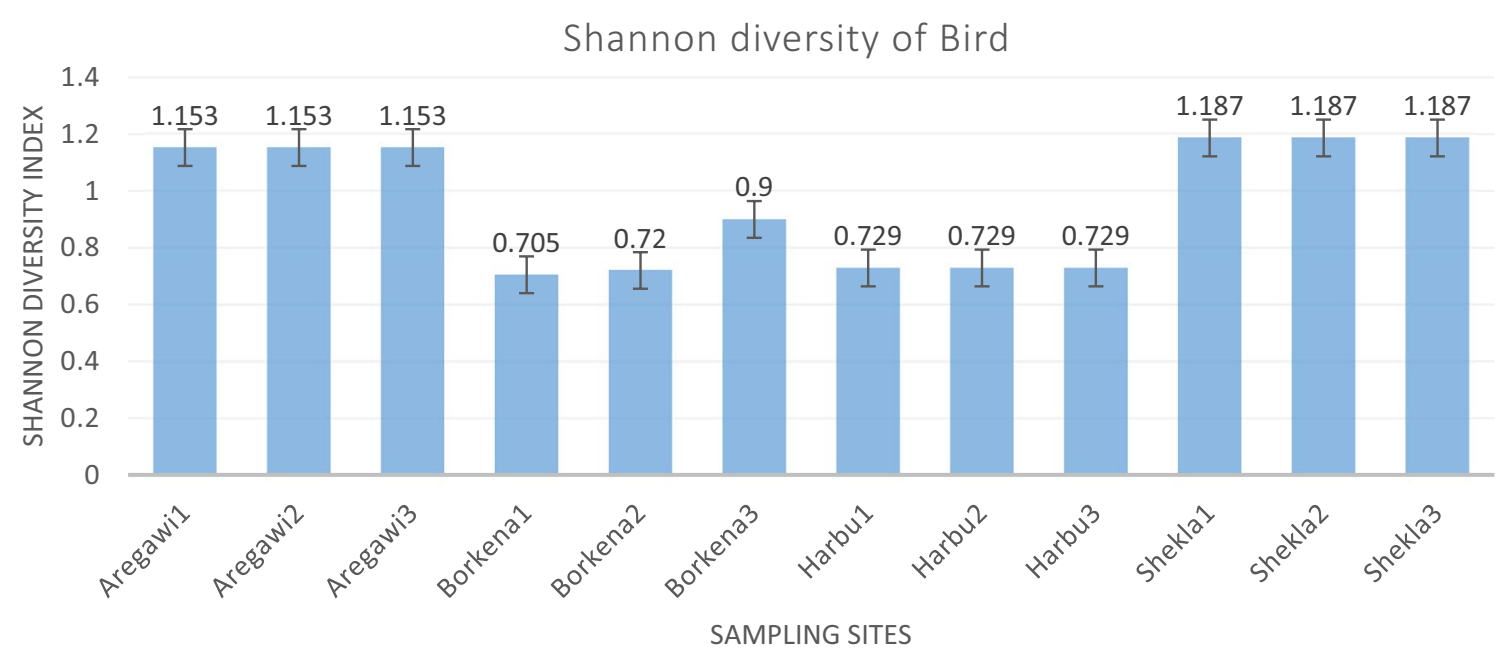

Fig. 7 Average Shannon diversity index calculated from birds in 12 sampling sites of hot springs in Eastern Amhara region, Ethiopia, 2013

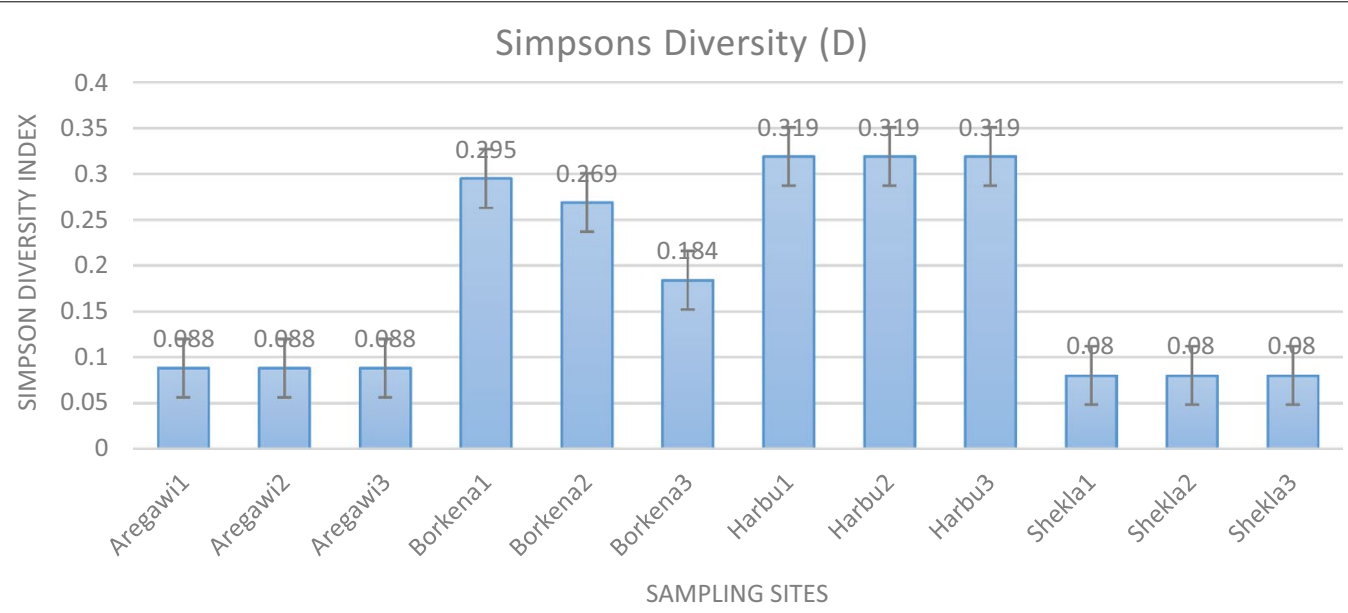

Fig. 8 Average Simpson diversity index (D) calculated from birds in 12 sampling sites of hot springs in East Amhara region, Ethiopia, 2013

this vegetation also reduces the wetland's anti pollution services because of the effectiveness of this species in reducing nitrogen and phosphorus levels in water (Abe et al. 1999) considered vegetation based indicators to be a promising tool for wetland nutrient conditions in areas where landscape disturbance is slight to moderate.

According to Chiputwa, Morardet, and Mano (Robledano et al. 2010) Water from the wetland was harnessed for a variety of purposes within the households, which include drinking, washing, bathing, irrigation, and building among others. Increasing drainage and cultivation of hot springs catchment and related wetlands when the water level recedes after the rains, has greatly affected the wetland ecosystem. Another study conducted in Mediterranean also showed that, human activities in wetlands threatened the existence of many birds by destroying their habitat or directly affecting their survival and on their reproductive success. This study further indicated that, the most important family Alaudidae (and particularly species like Melanocorypha Calandra) has lost due to degradation of wetlands, which were ideal habitats for roosting and thermoregulation (Robledano et al. 2010). This situation prevails also in the studied hot springs' wetland.

\section{Conclusion}

The study of hot springs in the Eastern Amhara region provides a preliminary assessment of what happens to be predominantly on temperature gradient, anthropogenic impacts, physicochemical parameters and other environmental variables on bird communities. The generally low bird diversity indicates an overall high water temperature, water quality degradation and vegetation disturbance effect throughout the hot 
springs, although variable correlations between water temperature and species diversity suggest a temperature gradient affects the overall sites. Longitudinal studies covering both wet and dry seasons are required to examine the hydrological influence on bird species and other similar biological communities by considering the origin, movement, soil profile, and minerals in surface and groundwater, as well as soil degradation and vegetation diversity, to better assess the relative contribution of anthropogenic and natural impacts. These studies can also validate and update the local bird index of hot springs initiated by the investigators. This broadly based biophysical information, together with detailed land use studies of the agricultural, pastoralist and urban communities may form the basis for a hot springs ecotourism framework that can inform managers and other decision makers at the local and state levels on taking integrated planning and preventive measures for further protection and sustainable use of the beauty of nature.

\section{Authors' contributions}

SD the main investigator and performing the study design, data collection and the overall data management and writing the manuscript. $A B$ has helped data analysis and application of software. MG is participating in two round data collection. AA has contributed in guiding and delivering constructive suggestions, participating in data management.

\section{Author details}

${ }^{1}$ Environmental Health Research Team, Ethiopian Public Health Institute, P.O. Box 1242, Addis Ababa, Ethiopia. ${ }^{2}$ Department of Environmental Health Sciences and Technology, Jimma University, P.O. Box 378, Jimma, Ethiopia. ${ }^{3}$ Department of Environmental Health, Wollo University, P.O. Box 1145, Dessie, Ethiopia.

\section{Acknowledgements}

We would like to acknowledge Jimma University for finical support for this research paper.

\section{Competing interests}

The authors have declared that they have not competing interest.

Received: 27 August 2015 Accepted: 8 October 2015

Published online: 26 October 2015

\section{References}

Abe K, Oza Y, Mizuta K (1999) Evaluation of useful plants for the treatment of polluted pond water with low Nand P concentrations. Soil Sci Plant Nutr 45(409):417

Barbour MT et al (1999) rapid bioassessment protocols for use in streams and wadeable rivers: periphyton, benthic macroinvertebrates, and fish. EPA 841 B 99 002, Washington, DC

Ambelu A, Lock K, Goethals P (2010) Comparison of modelling techniques to predict macroinvertebrate community composition in rivers of Ethiopia. Ecol Inform 5:147-152

APHA (1995) Standard methods for examination of water and wastewater. American Public Health association, Washington DC

Aynalem S, Bekele A (2008) Species composition, relative abundance and distribution of bird faunaof riverine and wetland habitats of Infranz and Yiganda at southern tip of Lake Tana, Ethiopia. Trop Ecol 49:199-209
Aynalem S, Bekele A, Getahun A (2008) Species diversity, distribution, relative abundance and habitat association of the Avian Fauna of modified habitat of Bahir Dar and Debre Mariam Island, Lake Tana, Ethiopia. Int J Ecol Environ Sci 34:259-267

Beyene A, Legesse W, Triest L, Kloos H (2009) Urban impact on ecological integrity of nearby rivers in developing countries: the Borkena River in highland Ethiopia. Environ Monit Assess 153:461-476

Brazner JC et al (2007) Evaluation of geographic, geomorphic and human influences on Great Lakes wetland indicators: a multi assemblage approach. Ecol Ind 7:610-635

Camargo JA, Gonzalo C, Alonso Á (2011) Assessing trout farm pollution by biological metrics and indices based on aquatic macrophytes and benthic macroinvertebrates: a case study. Ecol Ind 11:911-917

De Pauw N, Gabriels W, Goethal PM (2006) River monitoring and assessment methods based on macroinvertebrates: biological monitoring of rivers: applications and perspectives. Wiley, New York, pp 113-134

Dominguez Granda L, Lock K, Goethals PM (2011) Using multi target clustering trees as a tool to predict biological water quality indices based on benthic macroinvertebrates and environmental parameters in the Chaguana watershed (Ecuador). Ecol Inform 6:303-308

Gamito S (2010) Caution is needed when applying Margalef diversity index. Ecol Ind 10:550-551

Getachew M et al (2012) Ecological assessment of Cheffa Wetland in the Borkena Valley, northeast Ethiopia: macroinvertebrate and bird communities. Ecol Ind 15:63-71

Habitat UN (2005) A guidebook for local catchment management in cities. Communication Consultants, Nairobi

Haki GD, Gezmu TB (2012) Physico chemical properties of waters from some Ethiopian hot springs and the risk to the health of the community. Greener J Phys Sci 2(138):140

Hering D et al (2003) The development of a system to assess the ecological quality of streams based on macroinv ertebrates — design of the sampling programme within the AQEM project. Int Rev Hydrobiol 88:45-361

Kotze DC et al (2012) A rapid assessment method for coupling anthropogenic stressors and wetland ecological condition. Ecol Ind 13:284-293

Langford TL et al (2009) Long term recovery of macroinvertebrate biota in grossly polluted streams: recolonisation as a constraint to ecological quality. Ecol Ind 9:1064-1077

McKee J (2007) Ethiopia: country environmental profile. EC Delegation, Addis Abeba

MDEP (Maine Department of Environmental Protection) (2009) Quality assurance project plan for biological monitoring of Maine's rivers, streams, and freshwater wetlands. Augusta Maine: Bio Monitoring Program, QAPP Bureau of Land and Water Quality

Mekonnen T, Aticho A (2011) The driving forces of Boye wetland degradation and its bird species composition, Jimma, southwestern Ethiopia. J Ecol Nat Environ 3(365):369

Minaya $\vee$ et al (2013) Scale dependent effects of rural activities on benthic macroinvertebrates and physico chemical characteristics in headwater streams of the Mara River, Kenya. Ecol Ind 32:116-122

Oliver J, Venter JS, Jonker CZ (2011) Thermal and chemical characteristics of hot water springs in the northern part of the Limpopo Province, South Africa

Perlo B (2009) A field guide to the birds of East Africa. Collins, London

Piguet F (2002) Cheffa valley: refuge for 50,000 pastoralists and 200,000 animals. UN Emergencies Unit for Ethiopia, Addis Ababa

Robledano F et al (2010) Terrestrial birds as indicators of agricultural induced changes and associated loss in conservation value of Mediterranean wetlands. Ecol Ind 10:274-286

Rosenberg D, Resh V (1993) Freshwater biomonitoring and benthic macroinvertebrates. Chapman \& Hall, New York

Rosgen D (1996) Applied morphology. applied river morphology. Wildland Hydrology, Lakewood, Colorado

Smith B, Wilson JB (1996) A consumer's guide to evenness indices. Oikos 76:70-82

Tamene B, Bekele T, Kelbessa E (2000) An ethnobotanical study of the semi wetland vegetation of Cheffa

Torrisi M et al (2010) Comparative monitoring by means of diatoms, macroinvertebrates and chemical parameters of an Apennine watercourse of central Italy: the river Tenna. Ecol Indic 10:910-913 
Turkmen G, Kazanci N (2010) Applications of various diversity indices to benthic macroinvertebrate assemblages in streams of a natural park in Turkey. BALWOIS
USEPA (2002) Methods for evaluating wetland condition: biological assessmen methods for birds. Office of Water, U.S. Environmental Protection Agency, Washington

\section{Submit your manuscript to a SpringerOpen ${ }^{\odot}$} journal and benefit from:

- Convenient online submission

- Rigorous peer review

- Immediate publication on acceptance

- Open access: articles freely available online

- High visibility within the field

- Retaining the copyright to your article

Submit your next manuscript at $\gg$ springeropen.com 